\title{
How I Treat Epithelial Ovarian Cancer during COVID-19 Pandemic
}

Coronavirus disease 2019 (COVID-19) pandemic is accelerating in an unprecedented manner, with 3,175,207 confirmed cases and 224,172 deaths worldwide. ${ }^{[1]}$ Studies from China and Italy reported that individuals with cancer have a two-fold higher rate of COVID-19 infection and a ten-fold higher risk of mortality as compared to individuals patients without cancer. ${ }^{[2-4]}$ Cancer caregivers are battling in the wake of a scarcity of workforce, personal protective equipment, medications, and risk of COVID-19 infection. This catastrophic situation warrants a relook of management of epithelial ovarian cancer adapted to the local context. Various guidelines on ovarian cancer management and publications of landmark trials were reviewed in this regard, and the latest literature on COVID-19 was studied. ${ }^{[5,6]}$ These are the suggestions from science and cost-care consortium for managing ovarian cancer patients during the COVID-19 pandemic [Table 1].

\section{Newly Diagnosed Ovarian Cancer}

The intent of early-stage (I/II) ovarian cancer is curative, so it should be managed with primary debulking surgery (PDS) and adjuvant chemotherapy for 3-6 cycles. In view of COVID-19, the European Society of Medical Oncology prioritize newly diagnosed ovarian cancer selected for PDS as a medium priority, and it can be deferred by 4 weeks. ${ }^{[7]}$ Similarly, the Society of Gynecologic Oncology (SGO) classifies PDS for newly diagnosed early-stage ovarian cancer as a Tier $2 \mathrm{~A} / \mathrm{B}$ (nonurgent) category of Modified Elective Surgery Acuity Scale and can be delayed by $4-12$ weeks. ${ }^{[8]}$ There is no change in the standard surgical staging procedure for PDS. An open approach should be considered rather than laparoscopy, as it can generate aerosols. ${ }^{[9]}$

Stage III/limited stage IV carcinoma ovary patients are managed with PDS followed by adjuvant chemotherapy or neoadjuvant therapy (NACT) followed by interval debulking surgery (IDS) and further adjuvant chemotherapy. The neoadjuvant treatment is employed to achieve rapid clinical response, low operative morbidity, and optimal debulking surgery. ${ }^{[10]}$ As prior surgery is associated with significant mortality in COVID-19 patients with cancer. ${ }^{[3]}$ Hence, it is vital to start NACT rather than PDS for a newly diagnosed patient of stage III/IV ovarian cancer. The recent COVID-19 guideline for SGO classifies IDS as Tire $3 \mathrm{~A} / \mathrm{B}$ (semi-urgent). The decision for IDS after 3-4 cycles of NACT can be delayed up to $1-4$ weeks..$^{[8,11,12]}$

The goal of adjuvant therapy after PDS or NACT is to consolidate the benefits achieved so far. Adjuvant chemotherapy is beneficial if it is started within 3-6-week postsurgery. ${ }^{[13,14]}$ Unless compelling, it is prudent to delay adjuvant therapy until 6-week post-surgery in the current scenario.

\section{Relapsed Ovarian Cancer}

Platinum-sensitive ovarian cancer should be treated aggressively, as the outcome is better as compared to platinum-resistant/refractory cancer. It can be treated with 4-weekly regimens such as liposomal doxorubicin-carboplatin instead of 3-weekly and weekly therapies. The 3-weekly therapies, such as carboplatin and paclitaxel, can be continued as 4-weekly to decrease the hospital footfall. ${ }^{[7]}$ Imaging should be done every two cycles to document treatment response. For chemotherapy responders, an early switch to oral maintenance therapy is warranted. Palliative chemotherapy for elderly or poor performance status employing weekly chemotherapy requires frequent hospital visits. These may be converted to 3-weekly regimens of single-agent carboplatin with an area under curve 5 (AUC-5) or carboplatin AUC-5 and paclitaxel $135 \mathrm{mg} / \mathrm{m}^{2}$ to mitigate the crisis. ${ }^{[15,16]}$ Primary prophylaxis with granulocyte colony-stimulating factor can be used to prevent leukopenia.

Platinum-resistant cancer can be managed with oral cyclophosphamide with bevacizumab with similar benefit as compared to the standard regimens employing intravenous chemotherapy and bevacizumab with a progression-free survival of 5 months and 6.7 months, respectively. ${ }^{[17,18]}$ For platinum-refractory carcinoma ovary, oral metronomic therapy with cyclophosphamide and etoposide or melphalan may be considered.

Recent evidence showed higher blood vascular endothelial growth factor (VEGF) levels in COVID-19 patients as compared to healthy controls. VEGF is a significant biomarker of endothelial injury and a potential therapeutic target in viral acute lung injury and acute respiratory distress syndrome (ARDS). VEGF inhibition may decrease hypoxia, improve endothelial permeability, and clinical trials are evaluating the role of VEGF inhibition in COVID-19. ${ }^{[19]}$ Thus, anti-VEGF drugs like bevacizumab may be continued with chemotherapy subject to patients' tolerance and treatment-emergent adverse reaction.

Low-grade serous ovarian carcinoma is usually treated with leuprolide, tamoxifen, aromatase inhibitor, trametinib, and fulvestrant. ${ }^{[20]}$ These agents are relatively safe and can be continued during the COVID-19 outbreak.

\section{Maintenance Chemotherapy}

Poly (ADP-ribose) polymerase (PARP) inhibitors such as olaparib are relatively myeloid and platelet sparing as compare to rucaparib or niraparib. Olaparib with or without bevacizumab can be continued as it has been associated with a minimal risk of febrile neutropenia. ${ }^{[21]} \mathrm{A}$ higher threshold for blood product transfusions in PARP 
Table 1: Summary of consensus opinions for managing ovarian cancer patients during the coronavirus disease 19 pandemic

\begin{tabular}{|c|c|c|c|c|}
\hline Clinical scenario & Surgery & Chemotherapy & Maintenance & Follow-up \\
\hline Newly diagnosed & PDS & Three weekly chemotherapy & \multirow[t]{2}{*}{ None } & \multirow{2}{*}{$\begin{array}{l}\text { Three monthly unless } \\
\text { clinically symptomatic }\end{array}$} \\
\hline Stage I/II & Delay 4-12 weeks & Delay up to 42 days post-PDS & & \\
\hline Newly diagnosed & Interval debulking & Three weekly NACT & \multirow{4}{*}{$\begin{array}{l}\text { Bevacizumab+olaparib/ } \\
\text { bevacizumab/observation } \\
\text { for BRCA wild } \\
\text { Olaparib for BRCA mutant }\end{array}$} & Monthly for olaparib \\
\hline Stage III/IV & after neoadjuvant & \multirow{3}{*}{$\begin{array}{l}\text { Delay adjuvant } \\
\text { chemotherapy } \pm \text { bevacizumab up } \\
\text { to } 42 \text { days post IDS }\end{array}$} & & \multirow{3}{*}{$\begin{array}{l}\text { Three monthly unless } \\
\text { clinically symptomatic }\end{array}$} \\
\hline Neoadjuvant & NACT preferred & & & \\
\hline candidate & Delay 1-4 weeks & & & \\
\hline Newly diagnosed & PDS & Three weekly chemotherapy & \multirow{3}{*}{$\begin{array}{l}\text { Bevacizumab+olaparib/ } \\
\text { bevacizumab/observation } \\
\text { for BRCA wild } \\
\text { Olaparib for BRCA mutant }\end{array}$} & Monthly for olaparib \\
\hline Stage III/IV & Delay 4-12 weeks & Delay adjuvant & & \multirow{2}{*}{$\begin{array}{l}\text { Three monthly unless } \\
\text { clinically symptomatic }\end{array}$} \\
\hline $\begin{array}{l}\text { Primary debulking } \\
\text { surgery candidate }\end{array}$ & & $\begin{array}{l}\text { chemotherapy } \pm \text { bevacizumab up } \\
\text { to } 42 \text { days post-PDS }\end{array}$ & & \\
\hline \multirow{3}{*}{$\begin{array}{l}\text { Platinum sensitive } \\
\text { relapse }\end{array}$} & \multirow{3}{*}{$\begin{array}{l}\text { Avoid/defer } \\
\text { secondary } \\
\text { cytoreductive surgery }\end{array}$} & Three weekly chemotherapy \pm & \multirow{3}{*}{$\begin{array}{l}\text { Olaparib for responsive } \\
\text { disease } \\
\text { Observation }\end{array}$} & Monthly for olaparib \\
\hline & & Bevacizumab & & \multirow{2}{*}{$\begin{array}{l}\text { Three monthly for } \\
\text { observation unless } \\
\text { clinically symptomatic }\end{array}$} \\
\hline & & Assess after 2 cycle & & \\
\hline $\begin{array}{l}\text { Platinum-resistant } \\
\text { relapse }\end{array}$ & $\begin{array}{l}\text { Avoid/defer } \\
\text { secondary } \\
\text { cytoreductive surgery }\end{array}$ & $\begin{array}{l}\text { Cyclophsphamide+bevacizumab/ } \\
\text { epoposide+cyclophsphamide/ } \\
\text { melphalan/olaparib for } \\
\text { BRCAmutant }\end{array}$ & Observation & $\begin{array}{l}\text { Three monthly for } \\
\text { observation unless } \\
\text { clinically symptomatic }\end{array}$ \\
\hline
\end{tabular}

PDS: Primary debulking surgery, NACT: Neoadjuvant chemotherapy

inhibitor-associated anemia may be used, and other correctable causes of anemia should be screened, such as iron, folate, and Vitamin B12 deficiency.

\section{Immune Checkpoint Inhibitor in Ovarian Cancer}

Unlike carcinoma lung, bladder, or melanoma carcinoma, epithelial ovarian cancer is less immunogenic, and in KEYNOTE 028 Ovarian cohorts, the overall response rate of an immune checkpoint inhibitor (ICI) is $11.5 \% .^{[22,23]}$ The clinico-radiologic features of an ICI-induced pneumonitis and COVID-19 pneumonia are indistinguishable. Further, in the systemic hyperinflammation stage of COVID-19 pneumonia, cytokines storm is responsible for ARDS and organ dysfunction. ${ }^{[24]}$ Patients receiving pembrolizumab (an anti-PD1 ICI) for microsatellite unstable ovarian cancer can further accelerate the immunological injury in COVID-19. In the absence of conclusive data to support or refute the use of ICI drugs in COVID-19, it will be prudent to make an informed decision to continue or stop after a detailed discussion with patients.

\section{Follow-up and Monitoring}

Those patients, who are under follow-up, can be monitored remotely by teleconsultations. The hospital visits for ultrasound, CA125 estimation can be deferred, and patients should visit the hospital only if they are symptomatic from malignancy - like rapid development of ascites and intestinal obstruction. ${ }^{[25]}$

The crux of managing ovarian cancer amidst the outbreak is the individualized approach with informed decision-making by the patient. Trading the risk of COVID-19 with perceived benefit from chemotherapy or immunotherapy is essential. Patient education, telephonic consultation, and relocating to a non-COVID-19 affected hospital should be our approach while actively treating a patient with epithelial ovarian cancer.

In summary, modifying chemotherapy regimens, minimizing hospital visits, and individualized treatment needed for the optimal management of ovarian cancer patients during the COVID-19 pandemic.

\section{Chandan Krushna Das ${ }^{1}$, Shubh Mahindru², Amol Patel ${ }^{3}$, Atul Batra ${ }^{4}$, Bivas Biswas ${ }^{5}$, Prashant Mehta ${ }^{6}$, Raja Pramanik ${ }^{4}$, Sainath Bhethanabhotla7, Vineet Govinda Gupta ${ }^{8}$}

${ }^{1}$ Regional Cancer Centre, Post Graduate Institute of Medical Education and Research, Chandigarh, India, ${ }^{2}$ Department of Surgical Oncology, Ivy Hospital, Ajitgarh, Punjab, India, ${ }^{3}$ Malignant Diseases Treatment Centre, Army Hospital Research and Referral, New Delhi, India, ${ }^{4}$ Department of Medical Oncology, All India Institute of Medical Sciences, New Delhi, India, ${ }^{5}$ Department of Medical Oncology, Tata Medical Center, Kolkata, West Bengal, India, ${ }^{6}$ Department of Medical Oncology/Hematology/Bone Marrow Transplantation, Asian Institute of Medical Sciences, Faridabad,

Haryana, India, ${ }^{7}$ Department of Medical Oncology, Krishna Institute of Medical Sciences, Secunderabad, Telangana, India, ${ }^{8}$ Department of Medical Oncology and Hemato-Oncology, Artemis Hospital, Gurugram, Haryana, India

Address for correspondence: Dr. Chandan Krushna Das, Regional Cancer Center, Post Graduate Institute of Medical Education and Research, Chandigarh, India. E-mail: ckdasoncology@gmail.com

Submitted: 29-Mar-2020

Revised: 07-Apr-2020

Accepted: 09-Apr-2020

Published: 16-May-2020 


\section{References}

1. WHO Coronavirus disease 2019 (COVID-19) Situation Report - 102.pdf [Internet]. Available from: https://www.who.int/docs/ default-source/coronaviruse/situation-reports/20200501-covid-19sitrep.pdf?sfvrsn=742f4a18_2. [Last cited on 2020 May 02].

2. Onder G, Rezza G, Brusaferro S. Case-Fatality Rate and Characteristics of Patients Dying in Relation to COVID-19 in Italy. JAMA. Published online March 23, 2020. doi:10.1001/ jama.2020.4683.

3. Liang W, Guan W, Chen R, Wang W, Li J, Xu K, et al. Cancer patients in SARS-CoV-2 infection: A nationwide analysis in China. Lancet Oncol 2020;21:335-7.

4. Yu J, Ouyang W, Chua MLK, Xie C. SARS-CoV-2 Transmission in Patients With Cancer at a Tertiary Care Hospital in Wuhan, China. JAMA Oncol. Published online March 25, 2020. doi:10.1001/jamaoncol.2020.0980.

5. NCCN Clinical Practice Guidelines in Oncology for Ovarian Cancer v1. 2020. Available from: https://www.nccn.org/professionals/ physician_gls/pdf/ovarian.pdf. [Last accessed on 2020 Mar 26].

6. Ledermann JA, Raja FA, Fotopoulou C, Gonzalez-Martin A, Colombo N, Sessa C, et al. Newly diagnosed and relapsed epithelial ovarian carcinoma: ESMO Clinical Practice Guidelines for diagnosis, treatment and follow-up. Ann Oncol 2013;24 Suppl 6:24-32.

7. ESMO. Management and Treatment Adapted Recommendations in the COVID-19 Era: Epithelial Ovarian Cancer. ESMO. Available from: https://www.esmo.org/guide lines/gynae cological-cancers/ esmo-manage ment-and-treatment-adapted-recommen dations-in-the-covid-19-era-epi thelial-ovarian-cancer. [Last accessed on 2020 Apr 02].

8. Surgical Considerations for Gynecologic Oncologists during the COVID-19 Pandemic. SGO; 2020. Available from: https://www.sgo.org/clinical-practice/manage ment/covid-19-resources-for-health-care-pract itioners/ surgical-considerations-for-gynecologic-oncologists-duringthe-covid-19-pan demic/. [Last accessed on 2020 Apr 06].

9. American College of Surgeons. COVID-19: Considerations for Optimum Surgeon Protection Before, During, and After Operation. American College of Surgeons; 2020. Available from: https://www.facs.org/covid-19/clinical-guid ance/ surgeon-protection. [Last accessed on 2020 Apr 70].

10. Kang S, Nam BH. Does neoadjuvant chemotherapy increase optimal cytoreduction rate in advanced ovarian cancer? Meta-analysis of 21 studies. Ann Surg Oncol 2009;16:2315-20.

11. Vergote I, Tropé CG, Amant F, Kristensen GB, Ehlen T, Johnson $\mathrm{N}$, et al. Neoadjuvant chemotherapy or primary surgery in stage IIIC or IV ovarian cancer. N Engl J Med 2010;363:943-53.

12. Onda T, Satoh $T$, Saito $T$, Kasamatsu $T$, Nakanishi $T$, Nakamura $\mathrm{K}$, et al. Comparison of treatment invasiveness between upfront debulking surgery versus interval debulking surgery following neoadjuvant chemotherapy for stage III/IV ovarian, tubal, and peritoneal cancers in a phase III randomised trial: Japan Clinical Oncology Group Study JCOG0602. Eur J Cancer 2016;64:22-31.

13. ElNaggar AC, Hade EM, O’Malley DM, Liang MI, Copeland LJ, Fowler JM, et al. Time to chemotherapy in ovarian cancer: Compliance with ovarian cancer quality indicators at a National Cancer Institute-designated Comprehensive Cancer Center. Gynecol Oncol 2018;151:501-5.

14. Flynn PM, Paul J, Cruickshank DJ, Scottish Gynaecological Cancer Trials Group. Does the interval from primary surgery to chemotherapy influence progression-free survival in ovarian cancer? Gynecol Oncol 2002;86:354-7.
15. von Gruenigen VE, Huang HQ, Beumer JH, Lankes HA, Tew W, Herzog $\mathrm{T}$, et al. Chemotherapy completion in elderly women with ovarian, primary peritoneal or fallopian tube cancer - An NRG Oncology/Gynecologic Oncology Group study. Gynecol Oncol 2017;144:459-67.

16. Parmar MK, Ledermann JA, Colombo N, du Bois A, Delaloye JF, Kristensen GB, et al. Paclitaxel plus platinum-based chemotherapy versus conventional platinum-based chemotherapy in women with relapsed ovarian cancer: The ICON4/ AGO-OVAR-2.2 trial. Lancet 2003;361:2099-106.

17. Barber EL, Zsiros E, Lurain JR, Rademaker A, Schink JC, Neubauer NL. The combination of intravenous bevacizumab and metronomic oral cyclophosphamide is an effective regimen for platinum-resistant recurrent ovarian cancer. J Gynecol Oncol 2013;24:258-64.

18. Pujade-Lauraine E, Hilpert F, Weber B, Reuss A, Poveda A, Kristensen $\mathrm{G}$, et al. Bevacizumab combined with chemotherapy for platinum-resistant recurrent ovarian cancer: The AURELIA open-label randomized phase III trial. J Clin Oncol 2014;32:1302-8.

19. Barratt S, Medford AR, Millar AB. Vascular endothelial growth factor in acute lung injury and acute respiratory distress syndrome. Respiration 2014;87:329-42.

20. Ricciardi E, Baert T, Ataseven B, Heitz F, Prader S, Bommert M, et al. Low-grade serous ovarian carcinoma. Geburtshilfe Frauenheilkd 2018;78:972-6.

21. LaFargue CJ, Dal Molin GZ, Sood AK, Coleman RL. Exploring and comparing adverse events between PARP inhibitors. Lancet Oncol 2019;20:e15-28.

22. Martincorena I, Campbell PJ. Somatic mutation in cancer and normal cells. Science 2015;349:1483-9.

23. Varga A, Piha-Paul S, Ott PA, Mehnert JM, Berton-Rigaud D, Morosky A, et al. Pembrolizumab in patients with programmed death ligand 1-positive advanced ovarian cancer: Analysis of KEYNOTE-028. Gynecol Oncol 2019;152:243-50.

24. Siddiqi HK, Mehra MR. COVID-19 illness in native and immunosuppressed states: A clinical-therapeutic staging proposal. Heart Lung Transplant 2020 Mar 20. doi: 10.1016/j. healun.2020.03.012 [Epub ahead of print]. Available from: https://www.jhlto nline.org/article/S1053-2498 (20) 31473-X/ abstr act. [Last accessed on 2020 Mar 26].

25. Rustin GJ, van der Burg ME, Griffin CL, Guthrie D, Lamont A, Jayson GC, et al. Early versus delayed treatment of relapsed ovarian cancer (MRC OV05/EORTC 55955): A randomised trial. Lancet 2010;376:1155-63.

This is an open access journal, and articles are distributed under the terms of the Creative Commons Attribution-NonCommercial-ShareAlike 4.0 License, which allows others to remix, tweak, and build upon the work non-commercially, as long as appropriate credit is given and the new creations are licensed under the identical terms.

For reprints contact: WKHLRPMedknow_reprints@wolterskluwer.com

\begin{tabular}{|l|l|}
\hline \multicolumn{2}{|c|}{ Access this article online } \\
\hline Quick Response Code: & Website: \\
& www.ijmpo.org \\
\cline { 2 - 2 } & DOl: \\
\hline
\end{tabular}

How to cite this article: Das CK, Mahindru S, Patel A, Batra A, Biswas B, Mehta $P$, et al. How I treat epithelial ovarian cancer during COVID-19 pandemic. Indian J Med Paediatr Oncol 2020;41:138-40. 